\title{
Third root of median nerve -a cadaveric study
}

\author{
Mohd.Saleem Itoo ${ }^{1 *}$, Raj Tajamul Hussain ${ }^{2}$, Omer Bashir Itoo ${ }^{2}$, Fahmida Akhter ${ }^{2}$, Gh.Mohd Bhat ${ }^{1}$, \\ Bashir Ahmed Shah ${ }^{1}$, Naseer Ahmad Shah ${ }^{3}$, Ab. Rashid Ganai ${ }^{4}$, Lateef Ahmad Wani ${ }^{4}$ \\ ${ }^{I}$ Associate Professor Department of Anatomy Government Medical College Srinagar J\&K, India \\ ${ }^{2}$ Assistant surgeon Department of Anatomy/Medicine Government Medical College Srinagar J\&K, India \\ ${ }^{3}$ Lecturer Department of Anatomy Government Medical College Srinagar J\&K,India \\ ${ }^{4}$ Assistant Professor Department of pathology/surgery Government Medical College Srinagar J\&K, India \\ *Corresponding author E-mail: dr.saleem68@gmail.com
}

Copyright (1) 2014Itoo et al. This is an open access article distributed under the Creative Commons Attribution License, which permits unrestricted use, distribution, and reproduction in any medium, provided the original work is properly cited.

\begin{abstract}
The third root of median nerve though rare has definite embryological basis and clinical impact. The Present study was conducted in the postgraduate Department of Anatomy at Government Medical College Srinagar to study the variations in the number of roots of median nerve during routine dissection for academic purposes between 2001 -20014. Both upper limbs of 35 Indian cadavers were dissected out for routine anatomic teaching and simultaneously recording observations. It was observed that in one of the female cadavers the left median nerve had three roots (one medial and two lateral). The two lateral roots originated from the lateral cord and the medial root originated from medial cord of brachial plexus. The third root originated between the origins of the lateral root and the musculocutaneous nerve from lateral cord of brachial plexus. This anomalous root joined with the median nerve distal to the lateral root in the proximal third of arm. The third root of median nerve though rare is of great academic and clinical significance in Surgery, Neurophysiology, Orthopedics, Anaesthesiology, Sports medicine and Physiotherapy.
\end{abstract}

Keywords: Axillary Artery, Brachial Plexus, Cords, Coracobrachialis, Third Root of Median Nerve, Pronator Syndrome.

\section{Introduction}

In classical description the median nerve (labourer's nerve) originates by two roots from the lateral $(\mathrm{C} 5,6,7)$ and medial cords (C8, T1) of brachial plexus. These roots join in the form of letter ' $\mathrm{Y}$ ' and embrace the third part of axillary artery. The nerve enters the arm first lateral to the brachial artery and then crosses from lateral to medial side of this vessel by passing anterior to it near the insertion of coracobrachialis, further it descends medial to it and proceeds towards the cubital fossa where it lies posterior to the bicipital aponeurosis and anterior to the brachialis. It usually enters the forearm between the humeral and ulnar heads of Pronator teres muscle. The entrapment of median nerve at this level presents with features like that of carpal tunnel syndrome plus involvement of palmer cutaneous nerve. In the forearm it descends posterior and adherent to the flexor digitorum superficialis and anterior to the flexor digitorum profundus. About $5 \mathrm{~cm}$ proximal to the flexor retinaculum, it emerges behind the lateral margin of the flexor digitorum superficialis [2] and becomes superficial just proximal to the wrist between the tendons of flexor digitorum superficialis and flexor carpi radialis. The median nerve is the only branch of brachial plexus which passes deep to the flexor retinaculum into the palm where its compression leads to carpal tunnel syndrome. In the arm, median nerve gives vascular branches to brachial artery which carry sympathetic fibers and muscular branches to the pronater teres at a variable distance from elbow joint. It innervates all flexors in the forearm except Flexor Carpi ulnaris and the medial two digitations of flexor digitorum profundus which are supplied by the ulnar nerve. The median nerve then enters hand deep to the flexor retinaculum along with the tendons of flexor digitorum superficialis, flexor digitorum profundus and flexor pollicis longus. From here it gives a recurrent branch (the million dollar nerve) which innervates the lateral two lumbricals and muscles of the thenar eminence namely opponens pollicis, abductor pollicis brevis, and flexor pollicis brevis. It also gives digital cutaneous branches which supply the lateral three and a half digits on the palmer side, index, middle and ring finger on the dorsal side of the hand. The palmer cutaneous branch passes over flexor retinaculum and is therefore spared in carpal tunnel syndrome. 


\section{Materials and methods}

The present study was carried out in the Postgraduate department of Anatomy Government Medical College Srinagar, Kashmir, India by dissecting both upper limbs of 35 formalin preserved cadavers (32 males and 3 females) over a period of 14 years (2001-2014) for routine teaching purposes and recording observations. Both upper limbs $(n=70)$ were meticulously dissected out strictly following instructions given in the Cunningham s manual of practical anatomy [1] and observed for variations in the number of roots of median nerve. Appropriate photographs were taken and labeled as shown in fig, [1].

\section{Results}

During routine dissection of 70 upper limbs between 2001-2014, we observed that in one middle aged female cadaver, the left median nerve originated by three roots. The lateral root originated from lateral cord of brachial plexus, the medial root from medial cord. These two roots joined in the form of letter ' $Y$ ' in front of the third part of axillary artery and embraced it. The third root of median nerve originated from the lateral cord of brachial plexus between the origin of lateral root and musculocutaneous nerve as shown in the fig, [1]. This root joined with the median nerve as a separate entity on the lateral side of it and distal to its lateral root in the proximal third of arm. The remaining anatomical course and branching pattern of median nerve in this limb was normal. The origin, course and branching pattern of median nerve on the right side of this cadaver was normal.

\section{Discussion}

There are various reports in the literature about the variations in the origin, course, branching pattern and modes of termination of the median nerve. These variations are commonly encountered during surgical procedures, dissection and autopsy. A thorough anatomical knowledge of these variations is very useful for Surgeons, Orthopaedicians, Interventional Cardiologists, Radiologists, Neurophysiologists and Anaesthetists. Variations about the number the roots of median nerve have been reported by many workers.According to Bergman et al. [3], the branch of brachial plexus that joins the median nerve in the upper third of the arm qualifies as its root. Chauhan et al. (2002) [4] observed that median nerve originated by two lateral and one medial roots. Rakh. Rajendra S etal.(2012) [5] reported a case in which third root of median nerve was present bilaterally and it originated from musculocutaneous nerve. Saeed et al. (2003) [6] also reported a case in which median nerve had three roots unilaterally, the third root taking origin from lateral cord. Itoo M S et al. (2010) [7] reported a rare anomaly of brachial plexus, on the right side of an Indian male cadaver, where medial and lateral cords of brachial plexus joined and formed a common anomalous nerve. This nerve then divided into medial and lateral components. The lateral division further gave origin to a smaller branch proximally which pierced coracobrachialis muscle and continued as a large branch which supplied other muscles of the anterior compartment of arm. The larger medial branch continued as Median Nerve. N. Satyanarayana (2010)[8] reported a case where right median nerve had three roots, medial root from medial cord and two lateral roots from lateral cord. The larger medial branch continued as Median Nerve. Satyanarayana et al. (2008)[9] found a four rooted median nerve with three lateral and one medial root. Venieratos et al.[10] reported a communicating branch between musculcutaneous nerve and median nerve, this branch after originating from muculocutaneous nerve procceeds downwards and medially to join the median nerve in the lower third of arm. These workers [4], [6], [8] reported that extra roots of median nerve were present unilaterally. Thus the observation made in our present study are very similar to those made by earlier workers $[4,6,8]$ who also reported the existence of median nerve with three roots and the third root originating from the lateral cord. But our observations were discordant with those made by other workers [5, 9] who found that the third root of median nerve was present either bilaterally and originated from medial cord of brachial plexus. The observations made in our present study is totally different from our earlier one[7] where we found that the lateral and medial cords of brachial plexus join to form a single anomalous nerve which in turn divided into median and musculocutaneous nerves. It is now obvious that variations in formation of median nerve are not so rare. These variations have definite embryological basis and diverse clinical presentations. The upper limb buds appear by day 26 or 27 opposite the lower five cervical and upper two thoracic spinal segments. During the seventh week of intrauterine development condensation of mesenchyme near the base of limb bud occurs. From the dermatomyotome regions of the somites myogenic precursor cells migrate into the limb buds and later differentiate into myoblasts [11] which establish an intimate contact with the proliferating nerve fibers. This neuromuscular interaction is essential for their complete functional differentiation [12]. As the limb buds elongate, the muscle tissue splints into flexor and extensor compartments which are innervated by ventral and dorsal rami from spinal nerves respectively. To explain the directional growth of nerve fibers two theories have been put forward-the neurotropism or chemotropism hypothesis of Ramon y Cajal (1919) [13] and the principle of contact guidance of Weiss (1941) [14]. The theorey of Chemotropism states that axonal growth cones act as sensors to the concentration gradients of molecules in the environment and grow up the gradient towards the source, i.e. the target. However the contact guidance mechanism also operates in parallel with neurotropism. To conclude, the adhesion between proliferating neuron (growth cone) and surroundimg myocytes 
(future muscle) and extracellular matrix are influenced by many factors which includes several classes of cell surface molecules like Neuronal cell adhesion molecule (N-CAM) and L1, the cadherins, including N-cadherin and the integrin family. The latter is a group of cell surface receptors that are molecular heterodimers which recognise and bind to components of extracellular matrix [15], such as fibronectin, laminin and collagen. Thus, both cell-cell and cell-matrix interactions may be involved in axonal pathfinding. Any deviation of pathfinding from normal due to above captioned factors results in abnormal cell-cell i,e, (neuron-myocyte) adhesion, which manifests as abnormal innervation of a myocyte or mucle and explains the genesis of nerve anomalies.

\section{Summary and conclusion}

The anomalies of median nerve though rare have definite embryological basis and diverse clinical presentations. The commonest anomaly being Median nerve with three roots present unilaterally. The additional third root commonly originates from the lateral cord of brachial plexus. Bilateral anomalies of median nerve are less common. These anomalies present with a variety of confusing clinical features. Thus a sound knowledge of these anomalies is essential for academicians, surgeons, Orthopedicians, radiologists, interventional cardiologists and anaesthetists. The median nerve with extra roots is more likely to be involved in entrapment syndromes and while performing orthopaedic and other surgical interventions. It is also very difficult for anaesthetists to give infra clavicular and other nerve blocks in presence of these variations. Orthopaedicians also find it difficult to operate and manipulate shoulder joint in presence of these nerve anomalies. Injury to these variant nerves in the proximal third of arm can present with variety of clinical manifestations including sensory, motor, vasomotor and trophic changes [6].

Figure Legends

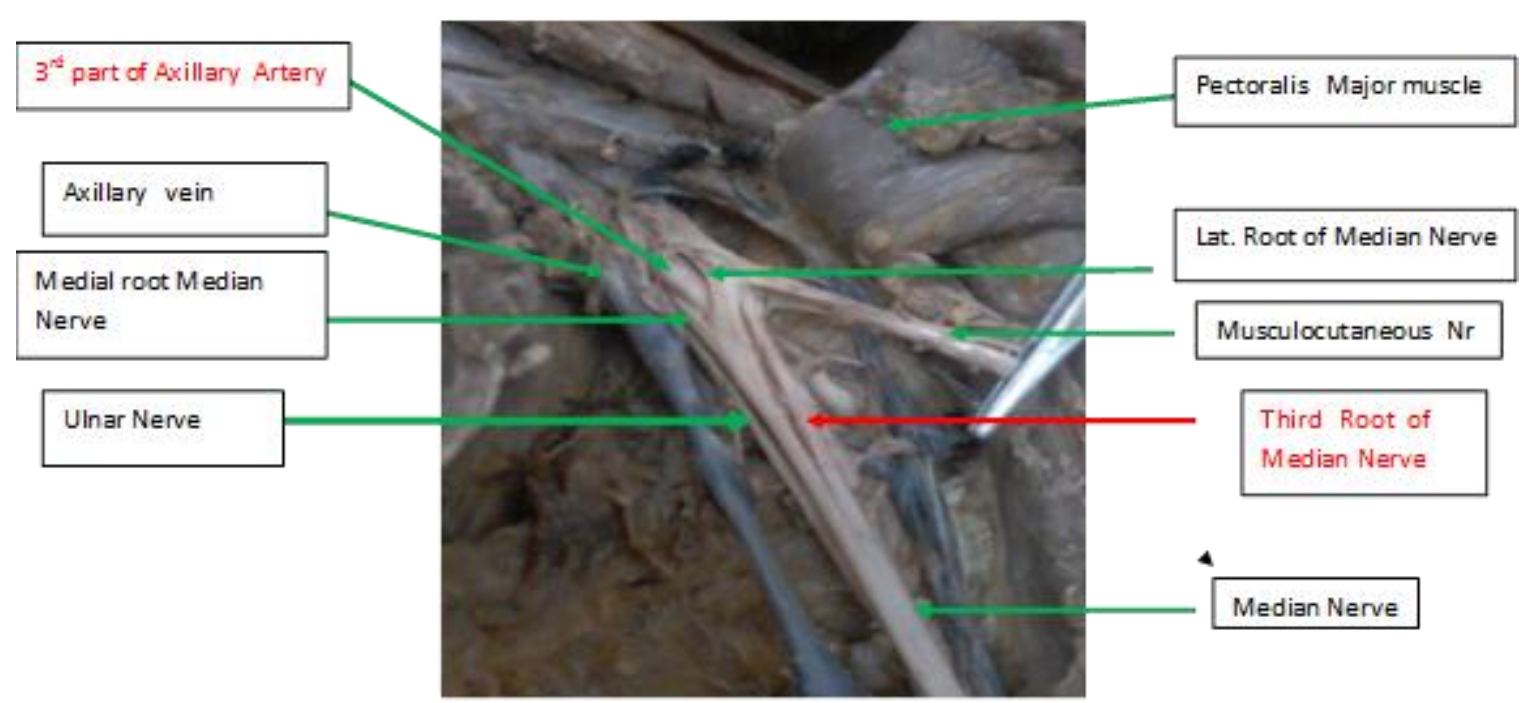

Fig. 1: Shows formation of left median nerve by three roots, one from the medial cord and two from the lateral cord of brachial plexus. The medial and lateral roots join in front of the third part of axillary artery to form the median nerve. The third root joins separately with the median nerve distal to the lateral root in the upper third of arm.

\section{References}

[1] Romanes GJ. Cunningham's Manual of Practical Anatomy. Volume 1, Upper and lower limbs. Oxford University Press. $1996 ; 167$.

[2] Standring S. Gray’s Anatomy. 38th Ed. Elsevier Churchil Livingstone. 2000; 1270-72

[3] Bergman R AN etal. Compendium of Human Anatomic Variation. Munich, Urban and Schwarzeberg,; 1988,139-143.

[4] Chauhan R.etal. Communication between median and musculocutaneous nerves; A case Report.J.Anat Soc India.2002;51:72-75.

[5] Rakh Rajendra.S etal, Bilateral presence of third root of median nerve; a case report International Journal of Anatomical Variations (2013 6:74-76.

[6] Saeed etal M, Median Nerve and musculocutaneous nerves; variant formation and distribution. Clinical Anat.2003; 16 ; $453-456$.

[7] Itoo M S etal. Anomalous origin and branching pattern of median and musculocutaneous nerve, KMJ, VOL: 4 No.2, April -june2010.

[8] N. Satyanarayana etal. Formation of median nerve by three roots; a case report.Journal of college of Medical science-Nepal 2010, Vol, 6, No.1, 47-50.

[9] Satyanarayana N etal,J Coll Med Sci. 2008;5:105-107.

[10] Venieratos D.etal. Classification of communications between musculocutaneous and median nerves Clinical Anat.1998; 11:327-331.

[11] KEITH L. MOORE, T.V.N.PERSAUD, The developing Human, Clinically Oriented Embryology, Eighth Edition, 368 -369.

[12] Saddler TW-Langman's Medical Embryology. 10 $0^{\text {th }}$ edition.Philadelphia Lippincott Williams \& Wilkins, 2006 ; $146-7$.

[13] Ramon y Cajal S. Accion neurotropic de los epitelios.Algunos detalles sobre el mecanismo genetic de las ramificaciones nerviosas intraepiteliales y sensoriales. Trab lab Invest Biol 1919; 17:65-8.

[14] Weiss P-Nerve Patterns:the mechanics of nerve.

[15] Standring S. Gray’s Anatomy. 38th Ed. Elsevier Churchil Livingstone.2000; 232. 